História (São Paulo)

\title{
Salvador, rainha destronada? (1763-1823) ${ }^{1}$
}

\section{Salvador, dethroned queen? (1763-1823)}

Pedro de Almeida VASCONCELOS*

Resumo Neste texto, será comentado o período que corresponde à perda da função de Salvador como capital colonial da América Portuguesa para a cidade do Rio de Janeiro (1763) até a "Independência na Bahia”, com a guerra e expulsão das tropas portuguesas em 2 de julho de 1823. Em primeiro lugar será efetuada uma análise sintética do contexto histórico do período, em diferentes escalas. Será destacado o ano de 1808, com a chegada da Corte joanina, momento em que serão lançadas as bases de superação de Salvador pelo Rio de Janeiro. Em seguida serão examinados os principais agentes sociais que atuaram no período, com destaque para os comerciantes e os traficantes de escravos, além da mudança do papel do Estado. Finalmente, importante para a Geografia Urbana Histórica, serão comentadas as principais transformações espaciais ocorridas na cidade de Salvador em comparação com algumas ocorridas no Rio de Janeiro, durante essas seis décadas, que pode ser considerado o último período de ascensão de Salvador, antes do início do seu longo declínio durante o Império e a República.

Palavras-chave: Capitais. Salvador. Rio de Janeiro. Ascensão. Declínio.

\begin{abstract}
This study will focus on the city of Salvador during the period between the ceding of its status as the colonial capital of Portuguese America to the city of Rio de Janeiro (1763), and the episode of the "Independence of Bahia", with the war and expulsion of the Portuguese troops on the July $2^{\text {nd }} 1823$. Firstly, the historical context of the period at varying levels will be analyzed. The year 1808 will be highlighted, a time at which the migraion of power towards Rio de Janeiro began, with the arrival of the Joanina Court. Then the main social agents of the period will be examined, in particular merchants and slave traders as well as the change in the role of the State. Finally, the main spatial transformations throughout the city that are of importance to Historical Urban Geography will be

\footnotetext{
* Ph.D em Geografia. Professor do Mestrado em Planejamento Territorial e Desenvolvimento Social da Universidade Católica do Salvador e do Mestrado em Geografia da Universidade Federal da Bahia. Pesquisador CNPq 1-A. Universidade Católica de Salvador, Avenida Garibaldi, n ${ }^{\circ} 2981$ Rio Vermelho, cep: 41940-450 - Salvador, BA - Brasil (pavascon@uol.com.br).
} 
described and compared to those which took place in Rio de Janeiro during these six decades. It will be proposed that this could be considered Salvador's last period of advancement before the start of a long phase of decline throughout the following years of Empire and then Republic.

Keywords: Capitals. Salvador. Rio de Janeiro. Ascent. Decline.

\section{Introdução}

A mudança da capital colonial de Salvador para o Rio de Janeiro em 1763 levou ao declínio imediato da capital baiana? Quais as perdas para a "Rainha destronada”? Podemos, inicialmente, colocar como hipótese que a cidade de Salvador não sentiu o impacto da mudança imediatamente e continuou sendo a principal cidade da colônia e a segunda do Império português até a independência. Em 1808, com a chegada da Corte de D. João VI, Salvador ainda era mais importante que o Rio de Janeiro, mas a nova capital recebeu então o impacto que permitiria sua consolidação, tendo em vista a sua ascensão provisória para capital do conjunto do Império. Finalmente, com a guerra da independência na Bahia (1822-1823), Salvador e o Recôncavo sofreram perdas importantes e, com a saída dos comerciantes portugueses, o seu declínio secular continuou no Império e na República até a segunda metade do século XX.

Neste texto, portanto, propomos discutir as questões e hipóteses levantadas, trazendo novos elementos para uma discussão que procura as articular mudanças políticas e suas relações com outros condicionantes econômicos e sociais, que obedecem a diferentes temporalidades.

\section{Os diferentes contextos}

No período entre 1763 e 1823 podemos destacar, no nível internacional, o impacto da revolução industrial na Europa do norte (c.1780); a independência dos Estados Unidos (1783), exemplo para as demais nações americanas; a revolução francesa (1789) e as guerras napoleônicas, com suas repercussões na América Latina e no Caribe, incluindo a transferência da Corte portuguesa para o Rio de Janeiro; a revolução escrava no Haiti (1791) e as independências hispano-americanas.

No espaço do Império português, as mudanças ocorridas anteriormente em função da descoberta do ouro em Minas Gerais, no final do século XVII, vão retirar a liderança econômica da parte norte da colônia, sobretudo da Bahia, além de dar início a um processo consolidado de interiorização da mesma. 
Os conflitos com os espanhóis na região platina vão aumentar a importância estratégica do sul da colônia. Por outro lado, a transferência da Corte, em 1808, já foi, em si, um evento excepcional: uma inversão, a colônia passando a sediar a administração metropolitana! Finalmente, ocorre outra excepcionalidade, não só com a forma monárquica do novo regime ao lado das novas repúblicas americanas, mas, sobretudo a constituição de um novo império com uma mesma família real implantada nos tronos da antiga metrópole (o pai, D. João VI) e no novo Estado (o filho, D. Pedro I). Por outro lado, enquanto no sul do novo império a independência foi alcançada de forma relativamente pacífica, no norte, sobretudo na Bahia, ocorreram sérias lutas pela independência até 2 de julho de 1823, quase um ano após a proclamação em 7 de setembro de 1822, com graves prejuízos na cidade e no Recôncavo, sem mencionar o início dos vários levantes africanos (PINHO, 1972).

No nível local, a situação não é apenas de perda: embora o êxodo provocado pela descoberta do ouro e, posteriormente, do diamante em Minas Gerais, tenha causado graves problemas na produção do açúcar, tendo em vista que a capitania da Bahia era a maior produtora da Colônia; por outro lado, o comércio baiano foi favorecido pela exportação de artigos e alimentos para a região mineira, e, sobretudo, pela enorme valorização do preço dos escravos. Já em 1703, Antonil informava que um oficial crioulo ou mulato valia o equivalente a 1,8 quilograma de ouro, enquanto uma que uma mulata valia 600 oitavas de ouro, o equivalente a mais de dois quilogramas (ANTONIL, 1981, p.170-171).

\section{Os principais agentes}

Tendo em vista os objetivos desde artigo, os agentes destacados serão sobretudo, o Estado, considerando a decisão política da transferência da capital da colônia em função de seus interesses estratégicos, mas também os agentes econômicos, devido à importância dos mesmos não só na economia local, como também na economia colonial e no conjunto do Império. Serão examinados os produtores agrícolas, os senhores de engenho e os plantadores de cana, assim como os indicadores de produção e de exportação do açúcar, e ainda os comerciantes, em plena ascensão no período, notadamente, os traficantes de escravos, que terão um destaque especial neste texto.

Quanto a Igreja, seu exame alongaria muito este artigo $^{2}$, mas é importante destacar que Salvador era a sede do Arcebispado desde 1676, e que sua jurisdição abrangia não apenas parte da colônia incluindo o bispado do Rio de Janeiro, como também as terras africanas de Angola e São Tomé e Príncipe, enquanto a atual região norte era subordinada diretamente ao Arcebispado de Lisboa. A 
realização do primeiro Sínodo em 1707 e a publicação das Constituições Primeiras do Arcebispado da Bahia em Salvador, refletem esta importância (VIDE, 2007).

\section{A) O Estado:}

Este período é iniciado como parte da gestão pombalina (1750-1777), tendo em vista a liderança do futuro Marques do Pombal, que entre outras medidas importantes tomadas anteriormente, já tinha ordenado a expulsão da ordem dos Jesuítas, em 1759. Ele foi o responsável pela mudança da capital para o Rio de Janeiro, levando em consideração questões de ordem estratégica, como as tensões e lutas com os espanhóis pelo domínio da região platina e pela consolidação da ocupação do sul da colônia, assim como pelo controle da exportação do ouro das minas com a tentativa de manter a exclusividade pelo porto do Rio de Janeiro.

A transferência da Corte portuguesa para o Rio de Janeiro, em 1808, com escala do regente em Salvador foi o fator fundamental para a consolidação dessa cidade, na medida em que ela foi transformada na capital (provisória) do Império, recebendo a transferência das principais instituições do Estado, assim como de parte da nobreza e da burocracia portuguesa.

A proteção da esquadra portuguesa por navios de guerra britânicos e a posterior influência britânica na economia e na política vão se refletir não só na abertura dos portos, realizada em Salvador, como também nos tratados desiguais que os favoreceram, bem como na tentativa de extinção do tráfico escravo.

Cabe destacarmos ainda outra perda: Salvador era a sede da Relação da América Portuguesa, sendo apenas subordinada ao Tribunal de Lisboa, mantendo sob a sua jurisdição parte do território africano. Como exemplo, os líderes do levante ocorrido em São Tomé, em 1744, foram julgados em Salvador.

A Bahia, em especial Salvador, perdeu duplamente: não só os governadores gerais e vice-reis serão nomeados para atuar no Rio de Janeiro, como esta cidade passou a ser a sede do Império português. As principais decisões que eram tomadas em Lisboa passaram a ser tomadas na nova capital. Por outro lado, a Capitania da Bahia ainda recebeu governadores de grande prestígio, como o Conde dos Arcos. 
B) Os agentes econômicos

Examinaremos, com maior destaque o papel dos produtores agrícolas, dos comerciantes e, especificamente, o dos traficantes de escravos.

\section{B1) Os produtores agrícolas}

Os senhores de engenho eram, sobretudo brasileiros, descendentes de portugueses com diferente grau de mestiçagem com indígenas, especialmente no período inicial da colonização. Eram considerados como a "nobreza da terra", e como "homens bons" dominavam a administração das câmaras municipais. Mas a produção agrícola, sobretudo a do açúcar para a exportação, sofria períodos de ascensão e de declínio, tanto diante da concorrência de outras regiões produtoras no Caribe, quanto da dependência do comércio monopolista colonial. Com a descoberta e a exploração das minas de ouro, e, posteriormente, de diamantes, a produção de açúcar sofreu com o êxodo de produtores que se deslocaram com seus escravos para a nova atividade extrativa, notadamente com o elevado aumento do preço dos escravos.

Por outro lado, eventos externos, como a revolução escrava no Haiti (1791), aumentaram a demanda pelo açúcar brasileiro, levando a momentos de recuperação e dinamismo na produção local. O Visconde de Carnaxide considerou os anos de 1795 a 1797 como o "período economicamente mais próspero, da província mais próspera, da que era a mais próspera colônia portuguesa” (CARNAXIDE, 1979, p.75).

Independentemente dos momentos de expansão e declínio, os produtores de açúcar viviam numa longa dependência dos comerciantes que financiavam as safras e se aproveitavam das dificuldades dos agricultores para controlar também parte da produção. Vale lembrarmos que as divisões entre agricultores brasileiros e comerciantes portugueses não era muito rígida, pois havia casamentos entre membros das elites da época, assim como alguns comerciantes se tornavam produtores agrícolas.

Os senhores de engenho, em geral, residiam em seus domínios agrícolas, em solares de grande importância como, por exemplo, o engenho Freguesia, no termo de Salvador, e realizavam grandes investimentos nas instalações produtivas, mas também nas de aparato ou de função religiosa, como a construção de capelas de dimensão equivalente a algumas igrejas da cidade de Salvador. Por outro lado, a maior parte dos senhores de engenho também tinha residências temporárias nas cidades, tanto no Recôncavo como em Salvador. 
Alguns dados sobre a produção agrícola do período ajudam a precisar a importância da Bahia, sobretudo do Recôncavo, em comparação com outras capitanias produtoras brasileiras. Entre 1804 e 1822, por exemplo, a Bahia exportou 10.523.000 arrobas de açúcar suplantando o Rio de Janeiro (8.505.000) e Pernambuco (6.933.000) (ARRUDA, 1980), o que é confirmado pelos viajantes Spix e Martius, que informaram que em 1817, com 511 engenhos, a Bahia exportava 27.300 caixas de açúcar, equivalentes a 1.200.000 arrobas, enquanto pelo porto do Rio de Janeiro eram exportadas 17.000 caixas, cerca de 680.000 arrobas (SPIX; MARTIUS, 1981, v 2, p. 154 e v 1, p.72), quase a metade da exportação baiana daquele ano. Em 1815 foi introduzida a máquina a vapor numa tentativa de modernizar o setor (ACCIOLI, 1931, p.64). Quanto ao fumo, a Bahia era responsável, no período, por mais de 90\% da produção da colônia, com cerca de 1.500 fazendas, totalizando uma produção anual de 35.000 rolos de fumo, exportados para Portugal e para a Costa da Mina (ALDEN, 1999, p.361).

\section{B2) Os Comerciantes:}

O comércio em Salvador, antes da abertura dos portos, estava sob o controle dos portugueses, que residiam e trabalhavam, em sua maioria, na Cidade Baixa. Eles gozavam de grande prestígio e estavam integrados, sobretudo, na Ordem Terceira do Carmo, assim como na irmandade de N. Sra. da Conceição da Praia. Os comerciantes portugueses financiavam a produção açucareira e controlavam boa parte das propriedades agrícolas que ficavam hipotecadas devido aos empréstimos realizados, juntamente com as instituições religiosas e leigas. Em 1800, o governador D. Fernando J. de Portugal já informava que o comércio da Bahia supria a produção do fumo, açúcar e outros gêneros, em “dinheiro, fazendas e escravos”, recebendo as colheitas em pagamento, havendo comerciantes que assistiam de 12 a 20 senhores de engenho ou de 300 a 400 lavradores de fumo (AMU, 2009, p.245), o que foi confirmado por Vilhena (1969, p.915) no mesmo período: “os senhores de engenho nada têm a maioria deles, que a aparência de ricos, pois que a maior parte das safras ... não chegam para satisfazerem aos comerciantes assistentes”.

Ainda em 1781, Silva Lisboa afirmou que a Bahia "fornece mais carga aos seus navios, do que nenhuma outra cidade do Brasil”, saindo 40 navios de 800 toneladas ou mais para Portugal (AMU, 2007, p.504). Vilhena (1969, p.56) afirmava, em 1799, que era “a praça da Bahia uma das mais comerciosas das colônias portuguesas”. 
Alguns dados sobre a exportação dos produtos baianos, liderados pelo açúcar, também nos revelam a importância das atividades do comércio a longa distância a partir de Salvador, também, de forma comparativa com o porto do Rio de Janeiro.

Em 1796 e 1797 a Bahia era ainda o maior porto exportador da Colônia, sendo superado pelo porto do Rio de Janeiro no período de 1798-1807 (considerando as exportações mineiras), mas essa posição ainda foi recuperada nos anos de 1808 e 1809; o Rio de Janeiro voltou a liderar nos anos de 1810 e 1811 (ARRUDA, 1980, p.141-142). No total das exportações, no período de 1796-1811, as do porto do Rio de Janeiro alcançaram o valor de 51.481.200\$957, enquanto as de Salvador atingiram 40.792.002\$972 (Idem, p.142). Em 1796, o ouro contava por 48\% das exportações do porto do Rio de Janeiro. Esse percentual caiu para 18,5\% em 1806 (Idem, p.157).

Quanto às importações, o porto do Rio de Janeiro liderou durante todo o período de 1796 a 1811, com exceção do ano de 1798 . No total foram importados $48.610 .724 \$ 349$ pelo porto do Rio de Janeiro e 34.560.069\$254 pelo porto de Salvador (Idem, p.148). Esses resultados mostram que, mesmo antes da chegada da Corte portuguesa, o porto do Rio de Janeiro passou a assumir o papel de principal porto colonial. Convém observarmos, porém, que o superávit do porto de Salvador era mais elevado (6,2 milhões contra 2,9 no Rio de Janeiro), certamente refletindo as elevadas despesas da Corte no Rio de Janeiro ${ }^{3}$.

Os comerciantes baianos tentaram reter o príncipe D. João em Salvador, oferecendo "um magestoso palacio" para o regente, o que foi recusado "em consequencia de temer o mesmo Principe a pouca segurança da barra e porto d'esta capital, que por isso reputava incapaz de servir de corte ...” (ACCIOLI, 1931, p.48). O comissário Balthasar da Silva Lisboa, com interessante visão estratégica, realizou o pedido para:

[...] que fosse transferida para aqui a sede da côrte estabelecida no Rio de Janeiro [...] a Bahia foi a primeira terra do Brazil povoada [...]; A abertura do porto por seo vistoso archipelago onde podem ancorar todas as armadas do mundo [...]; o seu incomparavel porto, o mais bello do mundo, está como no centro das colonias de $\mathrm{V}$. A. que dominando a Africa, lhe abre uma comunicação tanto mais facil e breve com a Asia, como com as nações alliadas da Europa, quanto fica sendo o seo commercio mais activo [...]. (ACCIOLI, 1931, p.231-232).

B3) Os traficantes de escravos:

Um destaque será dado aos traficantes de escravos devido à existência de poucos estudos que levam em consideração o impacto econômico da atividade. 
Salvador, rainha destronada? (1763-1823)

Em primeiro lugar, salientamos que, tanto no caso de Salvador, como também no de Recife e no do Rio de Janeiro, o comércio de escravos não obedecia ao chamado “tráfico triangular” sendo realizado diretamente entre os portos exportadores de escravos africanos e os referidos portos brasileiros ${ }^{4}$. Importantes quantias eram investidas na armação de barcos e equipes, em alimentos, na exportação de mercadorias de troca, sobretudo o fumo baiano, mas um enorme lucro era realizado, apesar do alto risco da travessia, risco ampliado com o início das atividades repressivas da marinha britânica a partir de 1810.

Uma primeira dificuldade consiste na definição: quem eram esses traficantes? Eram portugueses ou brasileiros? Desde meados do século XVIII um monopólio teria sido estabelecido sob o controle de 40 negociantes da Bahia e 20 de Pernambuco, com um limite de utilização de 24 navios para o tráfico de escravos (PINHO, 1982, p.312).

As instruções de 1779 assinadas por Martinho de Mello e Castro para o Marquês de Valença, mostram a visão metropolitana sobre este monopólio:

[...] gravissimos inconvenientes [...] a este Reino, em deixarmos o commercio da África, entregue nas mãos dos Americanos, lhes permittimos particularmente aos habitantes da Bahia e Pernambuco, huma ampla liberdade de poderem fazer aquella navegação e negociar em todos os portos daquelle Continente, não nos lembrando de acordar ao mesmo tempo [...] tivessem os portuguezes a preferência da mesma sorte que a Capital e os seus Habitantes a devem sempre ter em toda a parte sobre as colônias e habitantes dellas [...] [e] apropriarem-se alguns homens de negocio, da Bahia de todos os navios do commercio daquelle porto para a Costa de África e fazerem dele hum rigoroso monopólio (ACCIOLI, 1937, p.350-351).

Por outro lado, esses lucros ficavam nas cidades portuárias e deviam ser aplicados em várias atividades, desde os investimentos necessários para a continuação do tráfico, como a compra de barcos, equipamentos e manutenção de equipes (marinheiros, feitores, capelães etc.), como em investimentos em capelas igrejas, diante da mentalidade religiosa do período; e ainda em solares e outros imóveis residenciais e comerciais; no financiamento da produção agrícola etc. Já a partir de 1745, a capela do Senhor do Bonfim, foi construída por Teodózio Rodrigues de Farias, proprietário de três navios negreiros (VERGER, 1987).

Para o historiador Luiz Viana Filho, o tráfico era a atividade mais lucrativa da Bahia no século XVIII (VIANA FILHO, 1976, p.12). A informação de que 6.600 escravos foram vendidos da Bahia para as Minas entre 1760 a 1765, apesar da taxa de 9\$000 cobrada para cada escravo (AMU, p.104), pode dar uma ideia do lucro realizado diante dos preços elevados dos escravos nas regiões mineiras. 
Um dado avançado pelo historiador Pedro Calmon é fundamental: ele calculou que o valor de um navio negreiro, trazendo em torno de 400 escravos, vendidos a um preço médio de 140.000 réis, corresponderia a 60.000 cruzados, o equivalente ao investimento necessário para a implantação de seis engenhos de açúcar (!) (CALMON, 2002, p.108).

Por essas estimativas, e pelos sinais de riqueza acumulada por alguns traficantes, podemos levantar a hipótese de que, nos séculos XVIII e XIX, eles podem ter sido agentes equivalentes ou mesmo mais importantes para a economia da Bahia que os produtores de açúcar. Os preços dos escravos sempre foram elevados, e apesar da pressão inglesa até 1850, o lucro deste comércio deve ter sido um dos principais elementos sustentadores da economia baiana, o que ajuda a explicar a construção de magníficos prédios religiosos e civis em períodos de crise da produção açucareira.

Os dados para o período em exame são limitados, mas podemos levantar alguns indicadores. Por exemplo, nos anos de 1798-1810 a Bahia teria importado um total de 9.249:731\$441 réis da África e exportado 3.236:781\$675 réis, uma diferença de quase três vezes no valor das importações (ACCIOLI, 1980, p.51-53). De 1799 a 1807 a Bahia importou 29.191 escravos da Costa da Mina e 13.965 de Angola, totalizando 43.156 escravos num valor global de 4.036.300\$000 5 (ACCIOLI, 180?, p.321), o que corresponde a uma média de cerca de 93.500 réis por escravo, enquanto o preço médio dos escravos em Salvador, neste período, era de 140 mil réis, conforme informação de Vilhena (1969, p.109), o que nos dá outra idéia dos lucros realizados nesta atividade.

A captura pelos ingleses de 17 dos 32 navios negreiros, após 1810, resultou no fechamento de cinco das principais casas comerciais de Salvador em 1812 (MANCHESTER, 1973, p. 151), o que confirma a importância econômica do tráfico para a cidade. As perdas estimadas para a praça da Bahia, em 1815, foram calculadas em 1.048:295\$059 réis, enquanto para o Rio de Janeiro as perdas alcançaram apenas 93.161\$980 réis (TAVARES, 1988, p.20).

Maria Graham, informou em 1821 que Salvador era o principal porto de escravos do Brasil, e que 76 embarcações partiram em 1820 desta cidade para a costa da África, e mais grave ainda: "Um dos membros da Junta Provisória é o maior comerciante de escravos daqui"6. (TAVARES, 2001, p.224).

Em 1797 foram importados em Salvador 3.938 escravos em 18 navios da Costa da Mina e 580 em um navio de Angola (ACCIOLI, 1931, p.204). Em 1806 foram importados 8.037 escravos apenas da Costa da Mina (ACCIOLI, 1931, p.228). Spix e Martius estimaram uma importação de 12.000 
escravos por ano, em 1818, finalmente, o Barão de Roussin contabilizou a entrada de 16.000 escravos em 1821.(MATTOSO, 1973, p.121-137)

Os dados para Rio de Janeiro apresentam números ainda mais elevados. Southey informou que, em 1792, foram importados 8.412 escravos, tendo entrado naquele ano 20 navios procedentes da África (SOUTHEY, 1981, v. 3, p. 442-443). Luccock (1975, p.391) estimou um total anual de 10.000 escravos anuais, em 1818, transportados em navios com capacidade para 200 a 400 escravos, que faziam duas viagens por ano "agregando um capital de cerca de meio milhão de esterlinos". O residente inglês ainda acrescentou que o capital "é na sua maior parte... de origem brasileira". Spix e Martius informaram a chegada de 20.075 indivíduos dos portos da Guiné e de Moçambique, em 1817, o que permite a comparação com as estimativas feitas para Salvador pelos mesmos viajantes (SPIX; MARTIUS, 1981, v.1 p.70).

Em Salvador, destaca-se, no período, o traficante Domingos José Martins, que possuía, no bairro dos Barris, um casarão com 22 janelas, no qual foi hospedado Jerôme Bonaparte, quando de sua visita em 1806 (VERGER, 1981, p.131).

Um segundo traficante Manuel José Machado, era proprietário do solar da Boa Vista, cuja torre servia de observatório para a chegada dos navios negreiros (MATTOS, 1961, p.12). Esse solar já foi utilizado como prédio principal da Prefeitura Municipal de Salvador.

Outro traficante, José Cerqueira Lima, foi proprietário de 16 navios no período de 1822 a 1839 e possuía seu palácio no atual Corredor da Vitória ${ }^{7}$, local de preferência dos residentes ingleses após 1808, e que, após transformação, tornou-se residência dos Presidentes da Província, sede da Secretaria da Educação e Saúde e, atualmente, abriga o Museu de Arte da Bahia. Seus móveis e alfaias mobiliaram o Palácio do Governo durante a visita que D. Pedro II fez à cidade em 1859 (CALMON, 1978, p.61)

Pedro Rodrigues Bandeira também era traficante de escravos (VIANA FILHO, 1976, p.10), tinha propriedades urbanas em Salvador e rurais em Santo Amaro (MATTOS, 1961, p.60). Foi um dos três diretores (ACCIOLI, 1931, p.69) e um dos principais acionistas da Caixa de Descontos (CALMON, 1978, p.39), primeiro banco de Salvador. Ele era cunhado do primeiro Presidente da Província da Bahia e "reputado como o homem mais opulento da colônia" (WILDBERG, 1949, p.9).

Um dos maiores traficantes de Salvador, o Comendador Antonio Pedroso de Albuquerque, diversificou seu capital após o final do tráfico em 1850. Foi proprietário de 20 navios no período de 1824 a 1841. Após 1850 foi proprietário da fábrica de tecidos Todos os Santos, em Valença, a maior do 
império. Foi também proprietário da Companhia de Vapores Bonfim e Santa Cruz e era um dos diretores da Companhia de Navegação Bahiana (CALMON, 1978, p.150). Possuía ainda engenhos em Itaparica, São Francisco do Conde e Santo Amaro e um total de 560 escravos, conforme seu inventário de 1883 (NASCIMENTO, 1986, p. 185 e p.197). Sua residência foi transformada na sede do atual Hospital Espanhol (MATTOS, 1961 p.66). Seu escritório ficava na Cidade Baixa, em frente à baía, cuja área passou a ser denominada "Cais do Pedroso".

Por outro lado, para o Rio de Janeiro, temos a importante informação da doação do Palácio de São Cristóvão ${ }^{8}$ ao regente D. João VI pelo traficante Elias Antônio Lopes $^{9}$, o que mostra o seu peso econômico e a sua penetração social no período.

\section{As principais transformações espaciais}

Fica a questão: Com a mudança da capital para o Rio de Janeiro, o Estado deixou de investir ou Salvador perdeu a importância diante da prioridade da nova capital? Como continuaram a agir os agentes econômicos e outros agentes em relação a Salvador? A cidade começou a declinar ou ainda sua importância econômica permitiu a continuidade de investimentos, tendo em vista as importantes mudanças ocorridas no período, como a abertura dos portos e o fim do monopólio colonial? Qual a opinião dos contemporâneos?

Uma primeira comparação que pode ser realizada é a partir dos precários dados demográficos das estimativas do período. O residente Luccock estimou que o Rio de Janeiro, em 1808, teria 60.000 habitantes, não incluindo 29.000 crianças (LUCCOCK, 1975, p.28-29). O historiador Southey, para o mesmo ano, estimou 100.000 habitantes tanto para Salvador como para o Rio de Janeiro (SOUTHEY, 1981, p.433 e p.443). O príncipe Maximilian confirmou esta mesma estimativa para Salvador para os anos 1815-1817 (WIED, 1989, p.469). Os viajantes Spix e Martius, porém, deram uma estimativa favorável a Salvador: ela teria mais de 115.000 habitantes (incluindo os arrabaldes da Vitória e do Bonfim) enquanto o Rio contava com 50.000 almas antes da chegada da Corte, e eles estimaram em 110.000 habitantes em 1817, mesmo incluindo uma imigração de 24.000 portugueses (SPIX; MARTIUS, op. cit., v.2, p. 159 e v. 1, p. 52.)

Southey, tendo como base o ano de 1808, foi bastante claro: "Com transferir-se a sede do governo para o Rio de Janeiro, outra nenhuma perda, além da dignidade, sofreu São Salvador [sic]... continuando a ser uma das maiores, mais opulentas e florescentes cidades do Novo Mundo". 
(SOUTHEY, 1981, p.433) Aires de Casal não se posicionou, em 1815, “enquanto São Salvador [sic] era uma das maiores, das mais comerciantes e florescentes da América"(1976, p.232) o Rio de Janeiro também era "uma das mais consideráveis, populosas, ricas e comerciantes cidades da América" (Ibid., p.196). Maximiliano, por outro lado, afirmou em 1817: "Bahia uma importante cidade, que parece exceder de muito, em tamanho, o Rio de Janeiro...” (WIED, 1989, loc. cit). Spix e Martius, ainda em 1817, confirmavam a importância de Salvador: “A Bahia é sem dúvida a mais rica e mais ativa praça comercial de todo o Brasil” (SPIX; MARTIUS, 1817, p.154), ou seja, mesmo após o impacto da transferência da Corte, antes da independência, Salvador ainda se impunha como a principal cidade brasileira.

Uma série de empreendimentos foi realizada pela Coroa e pelos agentes econômicos que confirmam a continuidade da importância da cidade pós a mudança da capital: a criação do Corpo Regular de Artilharia (1765); o forte de São Marcelo (1772); o Hospital Militar (1778); o Celeiro Público e a Ópera Velha (1785); a Escola Médico-Cirúrgica, o primeiro estabelecimento de ensino superior na América Portuguesa; três companhias de seguros; a primeira tipografia; a primeira fábrica, de vidro; o Consulado inglês; (1808); o quartel da cavalaria (1809); o Passeio Público (1810); a primeira Biblioteca Pública do Brasil e a Aula Pública do Comércio (1811); o teatro São João (1812); o inicio da abertura do canal Mares-Jiquitaia (1816); a Praça do Comércio (atual Associação Comercial) e o forte da Jiquitaia (1817); o primeiro banco, a Caixa de Descontos; o Curso de Desenho Técnico (1818); e o Consulado francês (1820) ${ }^{10}$.

Quanto ao Rio de Janeiro, o Passeio Público é de 1783. A maior parte dos novos empreendimentos são posteriores à chegada da Corte em 1808:

[...] o Jardim Botânico, a Academia Real de Desenho, Pintura, Escultura e Arquitetura, a Imprensa Régia, a Escola Médico-Cirúrgica, a Biblioteca Real, a Academia de Marinha, a de Artilharia e Fortificações, o Teatro São João [...] (REIS , 1972, p.325).

Em 1817 já estavam instaladas no Rio de Janeiro fábricas de galões, de meias de seda, de chitas e de lonas (CASAL, 1976, p.158).

Esta rápida comparação mostra que, apesar do status imperial dos novos empreendimentos no Rio de Janeiro, aqueles implantados em Salvador aparecem como equivalentes. Ainda havia um equilíbrio entre as duas cidades, o que foi alterado cada vez mais, após a independência e a centralização realizada no Rio de Janeiro. 


\section{Conclusões}

O texto apresentado levanta elementos factuais confirmando a continuidade da importância de Salvador até seis décadas depois da mudança da capital para o Rio de Janeiro, o que deve relativizar a importância conferida às mudanças políticas. Um destaque especial foi dado ao papel dos traficantes de escravos. Por outro lado os atuais exemplos americanos de São Paulo, Nova York e Toronto, mostram que o status de capital política não é suficiente, em numerosos casos, para competir com as capitais econômicas.

\section{Notas}

\footnotetext{
${ }^{1}$ Título sugerido por Laurent Vidal com referência à tese de doutorado de Rinaldo César Nascimento Leite, A Rainha Destronada: discursos das elites sobre as grandezas e os infortúnios da Bahia nas primeiras décadas republicanas. São Paulo, PUC, 2005.

${ }^{2}$ Para o exame do período com mais detalhe, ver Vasconcelos (2002).

${ }^{3}$ Para um exame do nível de riqueza dos grandes comerciantes no Rio de Janeiro, no período de 1790 a 1830 ver Fragoso (1998).

${ }^{4}$ Desde 1699 um alvará autorizou o tráfico negreiro direto, sem passar pela metrópole (MARCADÉ, 1991, p. 76).

${ }^{5}$ ACCIOLI, op. cit., p. 321. Faltam os dados para os anos de 1801, 1803 e 1806.

${ }^{6}$ GRAHAM, Maria. 1990, p. 191. Entre os seis membros da junta foram indicados dois comerciantes: Francisco Antônio Filgueiras e José Antônio Rodrigues Vianna (TAVARES, 2001, p. 224).

${ }^{7}$ Esse palácio seria ligado à baía por um subterrâneo por onde entrariam os escravos. Ver Mattos, op. cit., p. 12.

${ }^{8} \mathrm{O}$ prédio foi avaliado em 400.000 cruzados ou $160.000 \$ 000$ réis, e teria 300 janelas envidraçadas, segundo texto de autor anônimo, citado em Cavalcanti (2004, pp. 999-100).

${ }^{9}$ Ver Florentino, 2002, p. 207, inclusive para o exame do patrimônio dos principais traficantes do Rio de Janeiro.

${ }^{10}$ Ver fontes em Vasconcelos (2002).
}

\section{Referências}

ACCIOLI, C. S. I. Memorias Historicas e Politicas da Bahia. Salvador: Imprensa Oficial, v. 3, 1931.

ACCIOLI, C. S. I. Memorias Historicas e Politicas da Bahia. Salvador: Imprensa Oficial, v. 5, 1937.

ALDEN, D. O período final do Brasil colônia, 1750-1808. In BETHELL, L. (org.) América Latina Colonial. v. 2. São Paulo: Edusp, 1999, p. 527-592.

ANTONIL, A. J. Cultura e Opulência do Brasil. Belo Horizonte: Itatiaia; São Paulo: Edusp, 1982.

ARRUDA, J. J. A. O Brasil no Comércio Colonial. São Paulo: Ática, 1980, p.361-376.

CALMON, F. G. Vida Econômico-Financeira da Bahia. Salvador: CPE, 1978.

CALMON, P. História Social do Brasil. V. 1. São Paulo: Martins Fontes, 2002. 
CARNAXIDE, Visconde de. O Brasil na Administração Pombalina. São Paulo: Nacional; Brasília: MEC, 1979.

CASAL, M. A. Corografia brasílica ou Relação histórico-geográfica do Reino do Brasil. Belo Horizonte: Itatiaia; São Paulo: Edusp, 1976.

CAVALCANTI, N. O Rio de Janeiro Setecentista. Rio de Janeiro: Jorge Zahar, 2004.

FLORENTINO, M. Em Costas Negras. São Paulo: Companhia das Letras, 2002.

FRAGOSO, J. L. Homens de grossa aventura. Rio de Janeiro: Civilização Brasileira, 1998.

GRAHAM, M. Diário de uma viagem ao Brasil. Belo Horizonte: Itatiaia; São Paulo: Edusp, 1990.

INVENTÁRIO dos documentos relativos ao Brasil existentes no Archivo de Marinha do Ultramar AMU. Annaes da Bibliotheca Nacional do Rio de Janeiro. Vol. XXXII (1914), docs. n. 6972; 10907; v. XXXVI (1916), doc. n. 20509.

LUCCOCK, J. Notas sobre o Rio de Janeiro e partes meridionais do Brasil. Belo Horizonte: Itatiaia; São Paulo: Edusp, 1975.

MANCHESTER, A. Preeminência Inglesa no Brasil. São Paulo: Brasiliense, 1973 [1933].

ARCADÉ, J. O quadro internacional e imperial. In MAURO, F. (coord.) Nova História da Expansão Portuguesa. Lisboa: Estampa, 1991, p. 17-90.

MATTOS, W. Panorama econômico da Bahia 1808-1860. Salvador: Manu, 1961.

MATTOSO, K. Q. Albert Roussin: testemunha das lutas pela independência da Bahia (1822), Anais do Arquivo do Estado da Bahia, Salvador, n. 41, p. 116-168, 1973.

NASCIMENTO, A. M. A. Dez Freguesias da Cidade do Salvador. Salvador: Fundação Cultural, 1986.

PINHO, W. História de um Engenho do Recôncavo. São Paulo: Nacional, 1982.

A Bahia - 1808-1856. In HOLANDA, S. B. (dir.). História Geral da Civilização Brasileira. II. O Brasil Monárquico. Dispersão e Unidade. São Paulo: D.E.L., 1972, p. 242-311.

REIS, A. C. F. A Província do Rio de Janeiro e o Município Neutro. In HOLANDA, S. B. (dir.). História Geral da Civilização Brasileira. II. O Brasil Monárquico. Dispersão e Unidade. São Paulo: D.E.L., 1972, p. 315-352.

SOUTHEY, R. História do Brasil. Belo Horizonte: Itatiaia; São Paulo: Edusp, 1981, v.3.

SPIX; J. B. von; MARTIUS, C. F. P. von. Viagem pelo Brasil: 1817-1826. Belo Horizonte: Itatiaia; São Paulo: Edusp, 1981.

TAVARES, L. H. D. Comércio proibido de escravos. São Paulo: Ática, 1988. 
História da Bahia. São Paulo: Ed. Unesp, 2001.

VASCONCELOS, P. A. Salvador: transformações e permanências (1549-1999). Ilhéus: Editus, 2002.

VERGER, P. Fluxo e refluxo do tráfico de escravos entre o Golfo de Benin e a baía de Todos os Santos. São Paulo: Corrupio, 1987, p.96-117. Notícias da Bahia - 1850. Salvador: Currupio, 1981.

VIANA F. L. O Negro na Bahia. São Paulo: Martins Ed.; Brasília: MEC, 1976.

VIDE, Dom S. M. Constituições Primeiras do Arcebispado da Bahia. Brasília: Senado Federal, 2007.

VILHENA, L. S. A Bahia no Século XVIII. Salvador: Itapuã, 1969.

WIED, M., P. von. Viagem ao Brasil. Belo Horizonte: Itatiaia; São Paulo: Edusp, 1989.

WILDBERG, A. Os Presidentes da Província da Bahia. Salvador: Beneditina, 1949.

Recebido em 08/02/2011

Aprovado em 28/03/2011 